\title{
Climate impact of transportation A model comparison
}

\section{Journal Article}

Author(s):

Girod, Bastien; Vuuren, Detlef P. van; Grahn, Maria; Kitous, Alban; Kim, Son H.; Kyle, Page

Publication date:

2013-06

Permanent link:

https://doi.org/10.3929/ethz-b-000068343

\section{Rights / license:}

In Copyright - Non-Commercial Use Permitted

\section{Originally published in:}

Climatic Change 118(3-4), https://doi.org/10.1007/s10584-012-0663-6 


\title{
Climate impact of transportation A model comparison
}

\author{
Bastien Girod • Detlef P. van Vuuren • Maria Grahn • \\ Alban Kitous • Son H Kim • Page Kyle
}

Received: 6 September 2011 / Accepted: 11 December 2012 / Published online: 8 January 2013

(C) Springer Science+Business Media Dordrecht 2013

\begin{abstract}
Transportation contributes to a significant and rising share of global energy use and GHG emissions. Therefore modeling future travel demand, its fuel use, and resulting $\mathrm{CO}_{2}$ emission is highly relevant for climate change mitigation. In this study we compare the baseline projections for global service demand (passenger-kilometers, ton-kilometers), fuel use, and $\mathrm{CO}_{2}$ emissions of five different global transport models using harmonized input assumptions on income and population. For four models we also evaluate the impact of a carbon tax. All models project a steep increase in service demand over the century. Technology change is important for limiting energy consumption and $\mathrm{CO}_{2}$ emissions, the study also shows that in order to stabilise or even decrease emissions radical changes would be required. While all models project liquid fossil fuels dominating up to 2050, they differ regarding the use of alternative fuels (natural gas, hydrogen, biofuels, and electricity), because of different fuel price projections. The carbon tax
\end{abstract}

Electronic supplementary material The online version of this article (doi:10.1007/s10584-012-0663-6) contains supplementary material, which is available to authorized users.

The views expressed are purely those of the author and may not in any circumstances be regarded as stating an official position of the European Commission.

B. Girod $(\bowtie)$

Swiss Federal Institute of Technology Zurich (ETH Zurich), Department of Management, Technology, and Economics, Chair of Sustainability and Technology, Weinbergstrasse 56/58, 8032 Zurich, Switzerland e-mail: bgirod@ethz.ch

B. Girod · D. P. van Vuuren

Department of Geosciences, Utrecht University, Heidelberglaan 2, 3584 Utrecht, The Netherlands

D. P. van Vuuren

PBL-Netherlands Environment Assessment Agency, P.O. Box 1, 3720 Bilthoven, The Netherlands

M. Grahn

Department of Energy and Environment, Physical Resource Theory, Chalmers University of Technology, 41296 Goeteborg, Sweden

A. Kitous

European Commission, JRC-IPTS, C/ Inca Garcilaso no 3, 41092 Seville, Spain

S. H. Kim • P. Kyle

Joint Global Change Research Institute, Pacific Northwest National Laboratory, 5825 University

Research Ct, Suite 3500, College Park, MD 20740, USA 
of $200 \mathrm{USD} / \mathrm{tCO}_{2}$ in 2050 stabilizes or reverses global emission growth in all models. Besides common findings many differences in the model assumptions and projections indicate room for further understanding long-term trends and uncertainty in future transport systems.

\section{Introduction}

Passenger and freight transportation globally contributes $19 \%$ of energy use and $23 \%$ of energy related $\mathrm{CO}_{2}$ emissions (IEA 2009). Many projections indicate that both energy use and $\mathrm{CO}_{2}$ emissions from transport could rise sharply in the future (IEA 2010; Schafer et al. 2010). In order to reach ambitious climate targets, however, as for other sectors a rapid reduction of transport GHG emissions will be required (IPCC 2007; UNFCCC 2010). The possible reduction in GHG emissions from transportation is evaluated in several individual model-based studies (Girod et al. 2012; Grahn et al. 2009; IEA 2010; Kitous et al. 2010; Kyle and Kim 2011; Schafer et al. 2010; Takeshita and Yamaji 2008). The results of the different models have, however, not been compared yet. This article aims to contribute to the emerging literature on model-based transport scenarios by comparing projections for direct $\mathrm{CO}_{2}$ emissions from a set of global transport models (integrated in larger energy/integrated assessment models) and evaluating the underlying trends. Such a quantitative model comparison is now possible given the fact that recently several of these models have been developed. The participating models are GCAM (Kyle and Kim 2011), POLES (Kitous et al. 2010), TIMER (Girod et al. 2012), IEA-MoMo (Fulton et al. 2009), and GET (Grahn et al. 2009). For the model comparison, we ran scenarios with harmonized input assumptions for income and population. The model comparison includes data on 10 underlying world regions and projections up to 2095. We also evaluate the projections for a diagnostic mitigation experiment in order to understand the models' results for mitigation questions.

The article is structured as follows: In section 2 we describe the framework for the model comparison and the conducted model harmonization. Next we present and discuss the model projections for direct $\mathrm{CO}_{2}$ emissions and their underlying trends. Finally, we offer our conclusions with respect to the model-based findings on the $\mathrm{CO}_{2}$ emissions from transportation.

\section{Method}

\subsection{Framework for comparison}

To structure the comparison in a systematic way we break-down the transport $\mathrm{CO}_{2}$ emissions into the following individual components, similar to the Kaya identity (Kaya 1990). Such an approach, for analyzing structural variables to compare different scenarios, was applied by IPCC (2000) and Girod et al. (2009) among others. To assess the reason for differences in the main variables we structure the equation into characteristics specific for the transport system:

$$
\mathrm{CO}_{2} e=\underbrace{\sum_{r, t}\left(\operatorname{Serv}_{r, t}\right.}_{\text {Service }} \cdot \underbrace{\sum_{m}\left(\operatorname { M o d e } _ { m } \cdot \sum _ { v } \left(\operatorname{Veh}_{v} \cdot \text { Eff }_{v}\right.\right.}_{\text {EnergyEfficiency }} \cdot \underbrace{\left.\left.\left.\sum_{f t} \text { Fuel }_{f t} \cdot e f_{f t}\right)\right)\right)}_{\text {Carbon Intensity }} \cdot\left[G t \mathrm{CO}_{2}\right]
$$

Here Serv describes the service level in physical indicators (i.e., passenger-kilometer $(\mathrm{pkm})$ for personal travel and ton-kilometer $(\mathrm{tkm})$ for freight). The service is provided by 
different transport modes (Mode, in percent) such as buses, cars, trucks, etc. Within each transport mode different vehicle types (Veh, in percent) are specified, that are characterized by different energy efficiency (Eff, MJ/pkm, MJ/tkm) for example for cars this includes internal combustion engine, hybrid electric and fuel cell vehicles. Finally the different fuel types (Fuel, shares) and the corresponding emission factors (ef, $\left.\mathrm{kg} \mathrm{CO}_{2} / \mathrm{MJ}\right)$ determine the $\mathrm{CO}_{2}$ emissions. The global $\mathrm{CO}_{2}$ emissions $\left(\mathrm{CO}_{2} e\right)$ result from summing up the product of these factors for regions $(r)$, modes $(m)$, vehicles $(v)$ and fuel types $(f t)$.

\subsection{Model scenarios and harmonization}

\subsubsection{Socio-economic drivers}

In order to compare the outcomes of the different models we use a common set of main drivers. Therefore we run all participating models with common income and population assumptions using the projections of the OECD Environmental Outlook baseline (OECD (2012), see Figures S1 and S2 for population and income projection in the 10 world regions).

Besides the baseline projections we evaluate the response of the transport system to a carbon tax rising from zero in 2015 to 200 USD per ton $\mathrm{CO}_{2}$ (equal to 733 USD per ton C) in 2050 and then held constant through the end of the century. The tax is applied equally to all sectors and all regions.

\subsubsection{Emission factor and energy system}

In order to estimate direct $\mathrm{CO}_{2}$ emissions we use the same emissions factors for all models (56.1 $\mathrm{tCO}_{2} / \mathrm{TJ}$ for natural gas, $71.5 \mathrm{tCO}_{2} / \mathrm{TJ}$ for oil and liquid fossil fuels). For biofuels, we use an emission factor of $22 \mathrm{tCO}_{2}$ per TJ to account for the GHG emission caused through land use change (Eisentraut 2010).

Since we want to focus on the differences in the transport technology, our comparison does not look into the changes in the remainder of the energy system. That is, in this analysis we focus on the tank to wheel energy use. We do not assign additional emissions to the transportation sector for upstream emissions from the conversion of coal and gas to liquid fuels; we therefore use the same emission factor for fossil-based liquid fuels. The energy models generating the share of different fuels do, however, include also the different well to tank emissions. Hence emissions from electricity and hydrogen production are affected by the applied $\mathrm{CO}_{2}$ tax, and since these sectors are relatively easy to decarbonize, emissions drop considerably in policy scenarios (Girod et al. 2012). Still, given the tank-to-wheel focus of this study, these carbon-free energy carriers are not assigned any emissions.

\subsubsection{Output variables}

Since the participating models differ in their respective level of detail, we aggregate some subcategories (e.g., two-three wheelers and cars) and leave out others (e.g., non-motorized modes). For comparison of totals (e.g. global $\mathrm{CO}_{2}$ emissions from transportation) we exclude air and water freight transport because they are not provided by all models. The regional resolution in each model includes 10 world regions (see Figure S1), but the analysis will focus on the global level. We use 2005 as the base year and focus on results up to 2050 as the results are more robust and policy relevant for this time horizon. Since energy models are also used to project $\mathrm{CO}_{2}$-emission beyond 2050 we also indicate trends up to 2095 . 


\subsection{Model description and comparison}

An overview of the drivers and approaches to calculate the total service demand, the mode split, and fuel use is given in Table 1. A specification of the approaches used to model future service demand, the competition between different technologies, and changes in the energy system as well as a detailed description of each participating model is provided as supplementary material; in addition, all models are described in literature (see references in Table 1).

\section{Results and discussion}

According to Eq. 1 we first show the total $\mathrm{CO}_{2}$ emissions. Next we analyze the trends in service demand, energy and carbon intensity. This allows us to systematically consider the reasons for differences in the emission trends, to contribute to a better understanding of the drivers for future $\mathrm{CO}_{2}$ emissions and to discuss how these are simulated by the different models.

\subsection{Baseline projections}

\subsubsection{Global emissions and structural drivers}

Figure 1 shows the trends in direct $\mathrm{CO}_{2}$ emissions projected by the different transport

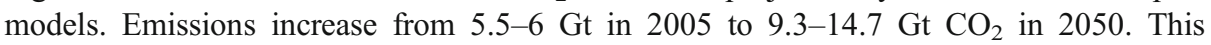
emissions range is similar to the range of baseline projections compared by Uherek et al. (2010). Cars and heavy trucks contribute to the largest share of total $\mathrm{CO}_{2}$ emissions, but all models project a steep increase in $\mathrm{CO}_{2}$ emissions from air travel. The low emissions projections from POLES and GCAM are comparable to the projections for road emissions of $7.5 \mathrm{Gt} \mathrm{CO}_{2}$ in 2050 by Takeshita (2011).

A look at the contribution of the different structural variables (cf. Eq. 1, Table S1) reveals that the low emissions in POLES and GCAM do not stem from lower service demand projections but rather higher energy efficiency improvements and decarbonization.

\subsubsection{Service demand}

Figure 2 shows that all models project a rapid increase in travel demand between 34 and 41 trillion pkm in 2005 to 86-141 trillion pkm in 2050. For historic travel demand Schafer et al. (2010) provide estimates for public transport (train and bus), car and air travel. During 1975 to 2005 higher travel growth (3.6\% per year) compared to GDP growth (3\% per year) could be observed. For future travel demand all models project saturation with increasing income, leading to a decoupling from GDP.

The high and low projections of POLES and GET can mainly be explained by their different assumptions about the growth in car travel (Table S2). Except for IEA, all models project a higher air travel growth than car travel demand, consistent with the historical time series. Still, all models' air travel growth projections are low compared to the projections of the International Civil Aviation Organization for 2006-2036 of 4 to $5.2 \%$ (ICAO/CAEP Forecasting and Economic Sub-Group 2008).

For the travel mode split, some differences can be observed for the base year (Fig. 2, Table S2). It should be noted that the uncertainty in the base year of historical data is high. This is particularly the case for buses, often the greatest portion of passenger travel in 


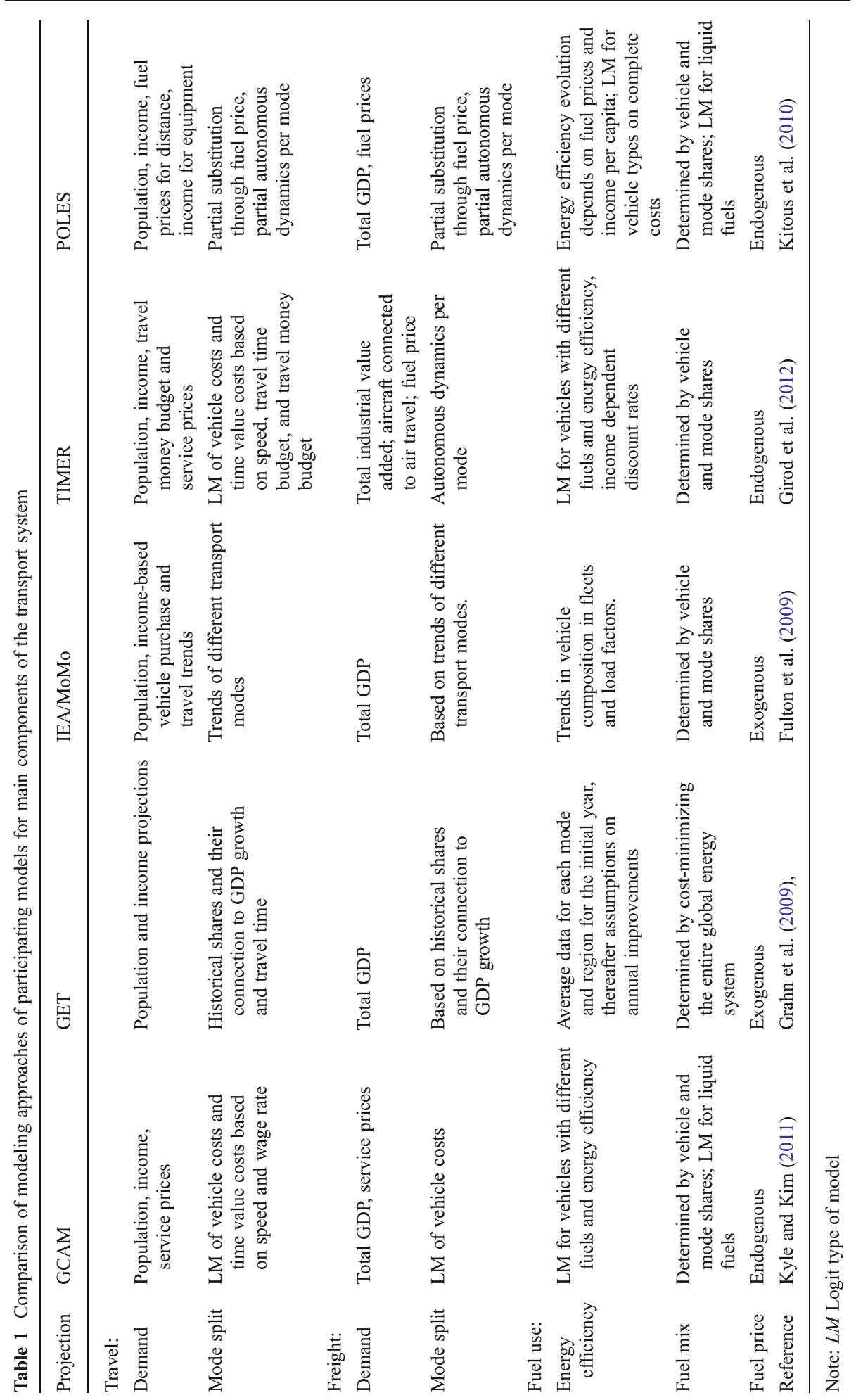



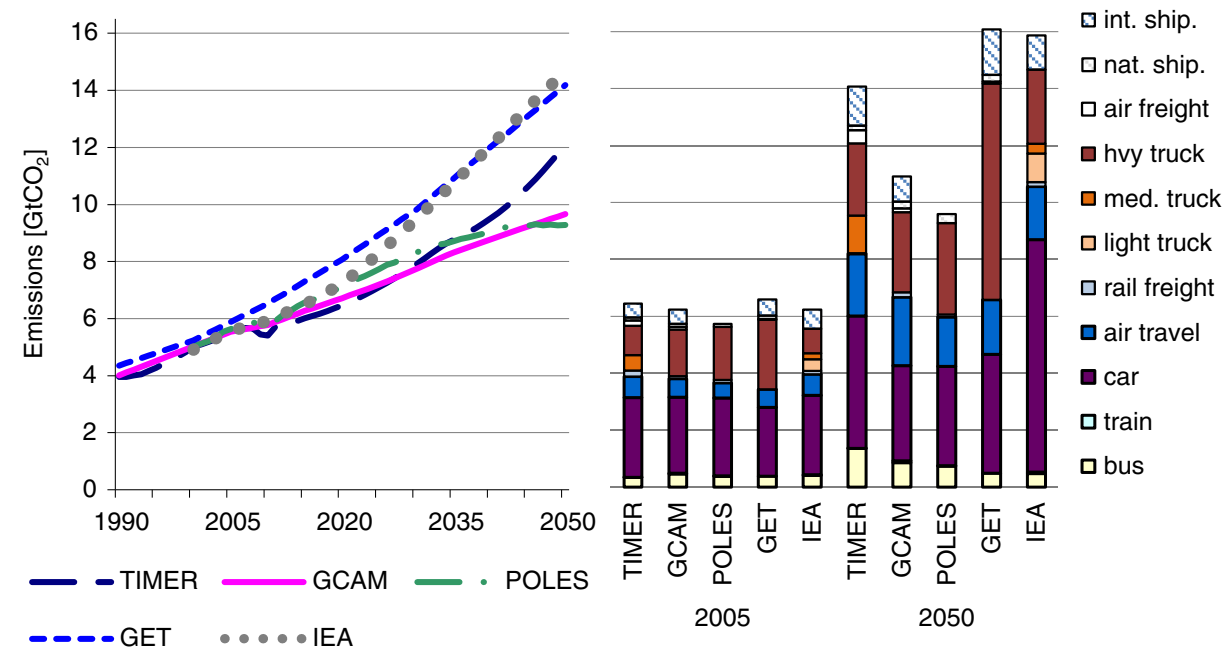

Fig. 1 Projections for global direct $\mathrm{CO}_{2}$ emissions from transportation. Left panel: Total volume for 1990 to 2050 for the baseline scenario (excluding air and water freight). Right panel: Contribution of different transport modes to direct $\mathrm{CO}_{2}$ emissions in 2005 and 2050

developing economies (Borken et al. 2007). This implies that the differences in base year data may be interpreted as a reflection of this uncertainty. The shift to faster transport modes in the future is most pronounced in models factoring time costs or considering constant travel time budget (TIMER, GCAM, GET). Schafer et al. (2010) projected an even higher share for high-speed modes of around $38 \%$ in 2050.

Light-duty vehicles continue to account for the majority of total travel in the different scenarios. In the three models considering high speed trains, the global share remains very low in 2050 (below $1.5 \%$ ).
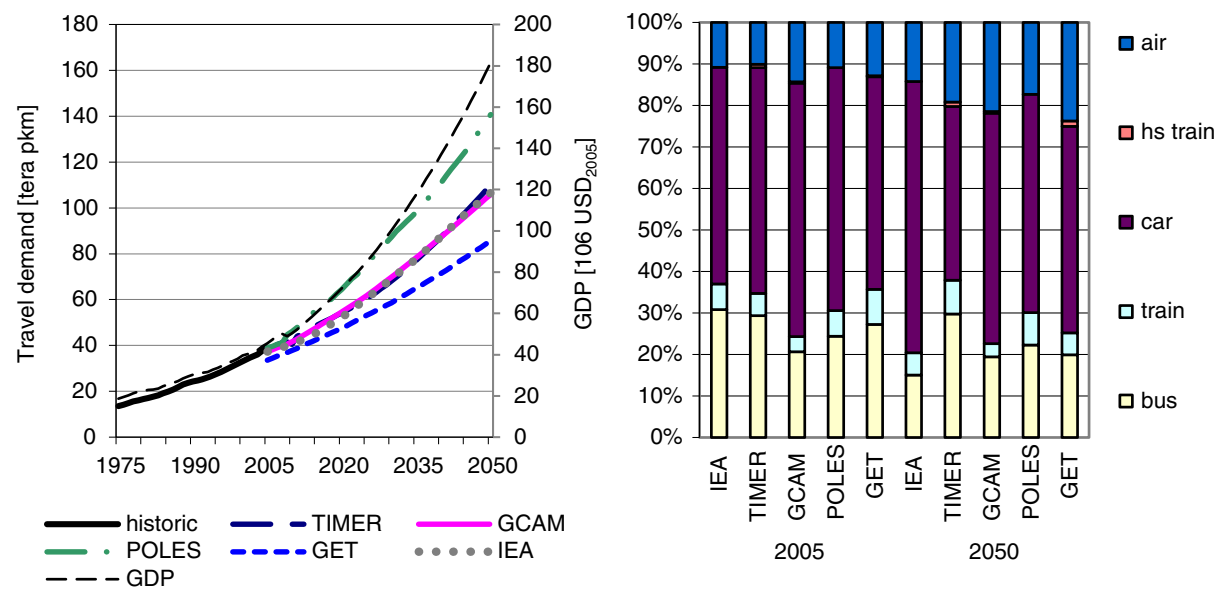

Fig. 2 Projected global travel demand in the baseline scenario. Left panel: Total volume [tera pkm] for 2005 to 2050 (and historical values for 1975-2005). GDP projection is displayed for comparison. Right panel: Modal split estimates for 2005 and projections for 2050 by the different models 
The freight demand projections (see Figure S3) show that all models assume a stronger decoupling from GDP compared to travel demand. The broad range of freight demand projections can be explained by the uncertainty in reliable statistics on global freight development. Regarding base year freight demand, the models come up with similar estimates for freight and rail, with two exceptions (Table S2): First, for heavy trucks, GCAM, GET, TIMER and POLES models assume a base year service demand of 8.2 to 10.1 trillion $\mathrm{tkm}$, while IEA assumes 5.8 trillion tkm. However, the previous IEA study (Fulton and Eads 2004) used also higher estimates (6.8 trillion tkm in 2000 and 7.8 in 2005). Second, POLES has a higher estimate for rail freight, which can be explained by a different definition of rail tkm, including also vehicle weight.

\subsubsection{Energy consumption}

Energy efficiency is an important driver for decoupling of GDP and $\mathrm{CO}_{2}$ emissions (cf. Table S1). Table 2 shows the global average energy intensity by mode in 2005, and the projected changes. Note that car, truck and aviation transport are much more energyintensive than bus, rail and ship transport. This explains why these modes account for larger shares of direct $\mathrm{CO}_{2}$ emissions than their shares in service demand. However, for mitigating $\mathrm{CO}_{2}$ emissions, rail transportation is important since it provides alternatives to the $\mathrm{CO}_{2}$ intensive transport modes. The differences in the base-year energy intensities are related to the uncertainty about historical fuel use and vehicle intensities, and especially to uncertainty in vehicle occupancy in developing and transforming countries (Borken et al. 2007). The high GCAM energy intensity for bus and rail stem from applying US energy intensity estimates to all regions, with only slight adjustments due to lack of consistent data sources.

Table 2 Global energy intensity projections (2005-2095)

\begin{tabular}{|c|c|c|c|c|c|c|}
\hline & \multicolumn{3}{|l|}{ Travel } & \multicolumn{3}{|l|}{ Freight } \\
\hline & Bus & Rail & Car & Air & Rail & Truck \\
\hline & \multicolumn{3}{|c|}{$2005[\mathrm{MJ} / \mathrm{pkm}]$} & \multicolumn{3}{|c|}{$2005[\mathrm{MJ} / \mathrm{tkm}]$} \\
\hline IEA & 0.50 & 0.30 & 2.05 & 2.54 & 0.09 & 2.82 \\
\hline TIMER & 0.41 & 0.33 & 1.83 & 2.63 & 0.37 & 2.30 \\
\hline GCAM & 0.86 & 0.70 & 1.65 & 1.70 & 0.21 & 2.48 \\
\hline POLES & 0.56 & 0.17 & 1.69 & 1.06 & 0.16 & 2.76 \\
\hline GET & 0.58 & 0.30 & 1.96 & 2.08 & 0.47 & 3.38 \\
\hline \multicolumn{7}{|c|}{2005 to 2050 [average $\%$ change per year] } \\
\hline IEA & $-0.5 \%$ & $-0.4 \%$ & $-0.5 \%$ & $-0.9 \%$ & $0.5 \%$ & $-0.5 \%$ \\
\hline TIMER & $0.9 \%$ & $0.5 \%$ & $-0.6 \%$ & $-1.2 \%$ & $-2.0 \%$ & $-0.2 \%$ \\
\hline GCAM & $-0.5 \%$ & $0.1 \%$ & $-0.9 \%$ & $-0.2 \%$ & $-0.4 \%$ & $-0.4 \%$ \\
\hline POLES & $-0.8 \%$ & $-2.1 \%$ & $-1.2 \%$ & $-2.5 \%$ & $-1.6 \%$ & $-0.8 \%$ \\
\hline GET & $-0.8 \%$ & $-0.2 \%$ & $-0.8 \%$ & $-1.0 \%$ & $-0.4 \%$ & $-0.6 \%$ \\
\hline \multicolumn{7}{|c|}{2045 to 2095 [average $\%$ change per year] } \\
\hline TIMER & $0.3 \%$ & $0.5 \%$ & $-1.0 \%$ & $-0.5 \%$ & $-0.3 \%$ & $-0.6 \%$ \\
\hline GCAM & $-0.1 \%$ & $-0.1 \%$ & $-0.2 \%$ & $-0.2 \%$ & $-0.1 \%$ & $-0.4 \%$ \\
\hline POLES & $-0.4 \%$ & $-0.5 \%$ & $-0.7 \%$ & $-1.0 \%$ & $-0.5 \%$ & $-0.5 \%$ \\
\hline GET & $-1.3 \%$ & $-0.2 \%$ & $-0.4 \%$ & $-1.0 \%$ & $-0.4 \%$ & $-0.7 \%$ \\
\hline
\end{tabular}


The low GCAM energy intensity for aircraft can be explained in part by lower estimates in the US Transportation Energy Data Book (Davis and Diegel 2011) compared to the IEA data (IEA 2009), and also due to GCAM's partitioning of aviation energy between passenger and freight services.

In the past 40 years, increases in vehicle efficiency in the US and Western Europe have been offset by increases in vehicle weight, power, and decreasing occupancy, resulting in constant historical energy intensities (Schafer et al. 2010). In contrast to this trend all models in this study project significant fuel efficiency improvements for cars from 2005 to 2050. The improvement of energy intensity per transport mode over time in the models can be a result of technological improvement or consumer choice, each of which may be influenced to varying degrees by energy prices. The projected efficiency improvements are in line with studies indicating considerable improvement in energy efficiency of future cars (Bandivadekar et al. 2008; Plotkin and Singh 2009).

For airplane historic development in the US, a decreasing energy intensity of $3.5 \%$ per year was observed from 1970 to 2005 (Schafer et al. 2010). In all models a decline in this energy efficiency improvement is assumed, which is consistent with estimates for the efficiency of new airplanes (Lee 2010). Except for POLES, the projections for energy intensity improvements are less optimistic than the projections from Lee (2010) of 1.2$2.2 \%$ per year, but within the range of the long term scenarios by Owen et al. (2010) $(0.2$ to $1 \%)$. The increasing energy intensity for bus and rail projected by TIMER in contrast to the other models can be explained by decreasing vehicle occupancy with increasing income assumed in this model.

Differences in the energy intensity are also related to estimates and projections for the fuel mix, especially the share of electricity and hydrogen (see Fig. 3). The latter fuels tend to reduce energy intensity, at least at the end-use level. To a certain extent, this is because only tank to wheel energy use is considered in this study. Accordingly, POLES projects highest efficiency improvement, which can be expained to a large extent explained largely by the highest share of these fuels (hydrogen and electricity), and vice versa for IEA. The highest

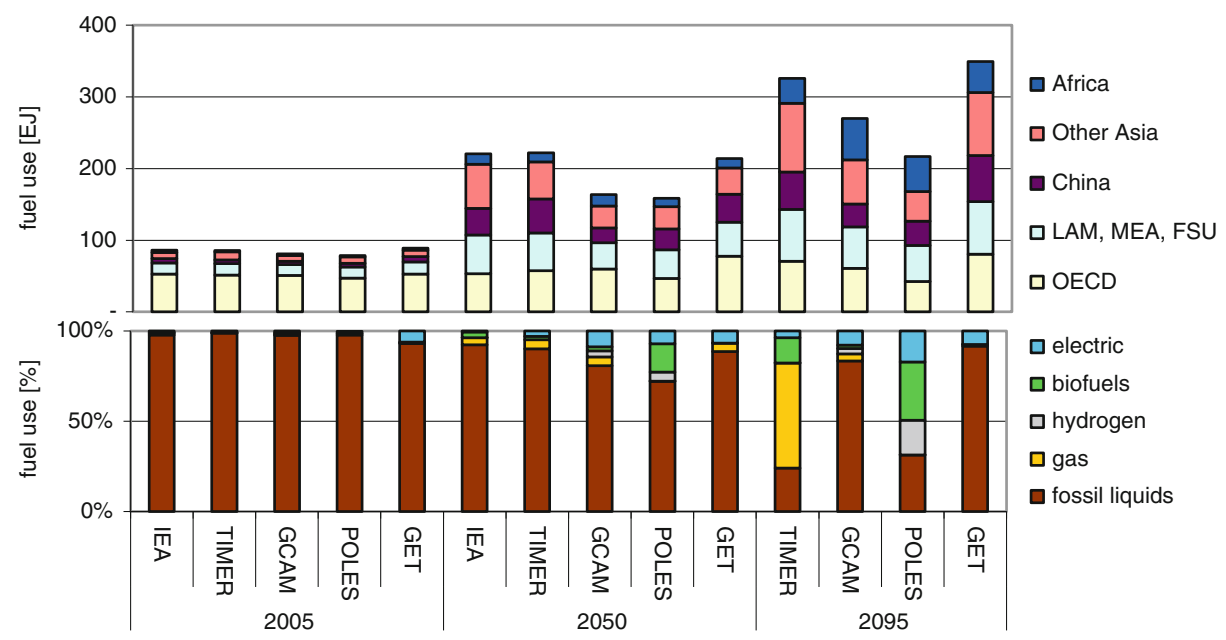

Fig. 3 Projected trends in fuel use in baseline scenario. Bottom panel: Composition of fuel for 2005, 2050, and 2095 for transportation (excluding air and water freight). Top panel: Regional fuel use projections for passenger transport and freight (excluding air and water freight). Note: Latin America (LAM), Middle East (MEA) and Former Soviet Union (FSU) 
efficiency improvements for POLES are consistent with the highest oil price projections (Figure S5).

For freight, the most pronounced difference in energy intensity improvement between the models is rail, which is much higher for TIMER than GCAM. This can also be explained by higher estimates for the future share of electric rail and uncertainties in data from developing regions.

As a result of the difference in mode shift and energy intensity, long-term projections for fuel use (see Figure S4) do not follow the trends in service demand. The projected range for fuel use in 2035 of $128-168$ EJ per year is around the value of 142 EJ projected by EIA (2011). With increasing shares of alternative fuels, trends in $\mathrm{CO}_{2}$ emissions and fuel use start to deviate.

\subsubsection{Carbon intensity (fuel mix)}

The fuel mix in 2005 is about $97 \%$ for oil and $1 \%$ for gas, biofuels and electricity, respectively, in all models (Fig. 3). Up to 2050 all models see liquid fossil fuels still dominating the fuel market, with the lowest share in POLES still being at $72 \%$. Very different projections exist for the alternative fuels: by 2050 in GET, TIMER and IEA only a marginal share of these fuels is in use, whereas in POLES biofuels gain a relevant share, and GCAM projects the highest share in electricity use.

The differences in projections on alternative fuels reflects the huge uncertainty (Krey and Clarke 2011), which can be attributed to technology evolution (cost performance, safety), regulatory environment, consumer choice and fuel prices. The fuel prices (Figure S5) reveal that IEA, TIMER and especially POLES project a strong increase in oil price. In TIMER and especially POLES, alternative fuels become cheaper than fossil fuels by 2050 . It should be noted that data availability for fuel prices is poor. As a result, models use different datasets for historical prices. Moreover, the prices reported here (global) are again an aggregate. The constant fuel prices in GET reflect the simplified model for the energy system (see section 2.3), where increasing extraction costs and technological learning for alternative fuels are not considered. GCAM has long-term price behavior and a relatively large resource base and thus shows little price increase. While fuel prices explain part of the shifts in fuel mix, vehicle cost (per type of fuel used) is also an important driver. For instance for electric cars the high battery costs are relevant.

\subsubsection{Trends beyond 2050}

The evaluation of the structural variables beyond 2050 (Table S1) reveals that in the second half of the $21^{\text {st }}$ century the models project very different trends in $\mathrm{CO}_{2}$ emissions. While POLES projects a decrease and TIMER a stabilization, GCAM and GET project a further growth in direct $\mathrm{CO}_{2}$ emissions from transportation by $0.9-1.2 \%$ per year. The different trends can be explained mainly by differences in assumptions of oil and gas supply potentials and availability of coal-based fuels, hence fuel prices and resulting fuel mix (Fig. 3). TIMER and especially POLES project fossil fuels to be more expensive than non-fossil fuels in the end of the century (see Figure S5). This explains also the higher energy efficiency improvement for TIMER and POLES compared to GCAM and GET (Table 2).

\subsubsection{Regional trends}

To evaluate the changes in the regional drivers for global $\mathrm{CO}_{2}$ emissions we focus on fuel use. Figure 3 shows fuel use for five large world regions. All models project a stabilization or 
decrease of fuel use in industrialized world regions (OECD) and a steep increase in developing and transforming regions, leading to a decline in the OECD fuel share from around $60 \%$ in 2005 to $24-37 \%$ in 2050 and $20-23 \%$ in 2095 .

The different trends in global energy growth up to 2050 are heavily influenced by the projections for Asia, with TIMER and IEA estimates around $100 \mathrm{EJ}$ and POLES and GCAM around 51 EJ. Because of saturation and relatively high certainty for OECD countries, future growth in global fuel use will be determined by how much other regions will grow. For developing regions, the data situation is quite poor (Borken et al. 2007) and the differences between the models can be interpreted as a reflection of this uncertainty. In all models, Africa is projected to amount to a larger share of global fuel use than China in the end of the century.

\subsubsection{Limitations of projections}

Despite a strong increase in transportation demand outside North America, no region projects a higher total per capita travel or freight demand than observed by 2005 in North America (see Table S3). Hence, the technical feasibility of the projected transportation demand in most regions is demonstrated by today's reality in North America. By 2050, only in North America the modeled activity level surpasses the historical data as a result of projected $30 \%$ increase in transport demand. Here, especially air travel shows a strong growth, most pronounced in the GET with an increase by a factor of four. This is, however, still below the projected six to ten fold increase by 2050 for North America from Schafer et al. (2010). Schafer et al. identify a number of measures that could allow for such an increase in travel demand without congestion, such as improvements to operational efficiency, new and larger airports, or the use of aircrafts with higher seating capacities.

The limitation from fossil fuel reserves also depends on the energy use in other sectors and the technological progress in using unconventional fossil resources and alternative energy for transportation. Such limitations are at least partially considered by the models (see section 2.3).

\subsection{Impact of carbon tax}

\subsubsection{Impact on $\mathrm{CO}_{2}$ emissions and aggregated driver}

Figure 4 shows total direct $\mathrm{CO}_{2}$ emissions for the baseline scenario with a carbon tax increasing to $200 \mathrm{USD}$ per ton $\mathrm{CO}_{2}$ in 2050. For such a tax all models project total emissions

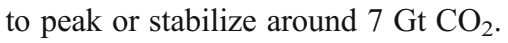

The contribution of the different factors in Eq. 1 to global emission reduction compared to the baseline shows that, while overall responses are similar, there are differences in where reductions are achieved (Table S4). In models that consider price sensitivity of service demand, a significant portion of emission reduction is due to lower demand levels. In contrast, changing mode split only contributes marginally to the emission reductions. For TIMER and POLES, the carbon tax tends to trigger, first, efficiency improvements, while for GCAM and GET it rather induces a change in the fuel mix.

The evaluation of the contributions of the different modes to the total $\mathrm{CO}_{2}$ emission reduction shows that most reductions come from cars and heavy trucks (Fig. 4), which is consistent with the conclusions from Uherek et al. (2010). In GET no reduction is seen from air transportation because the limited amount of biomass is more cost-effectively used in other energy sectors. 

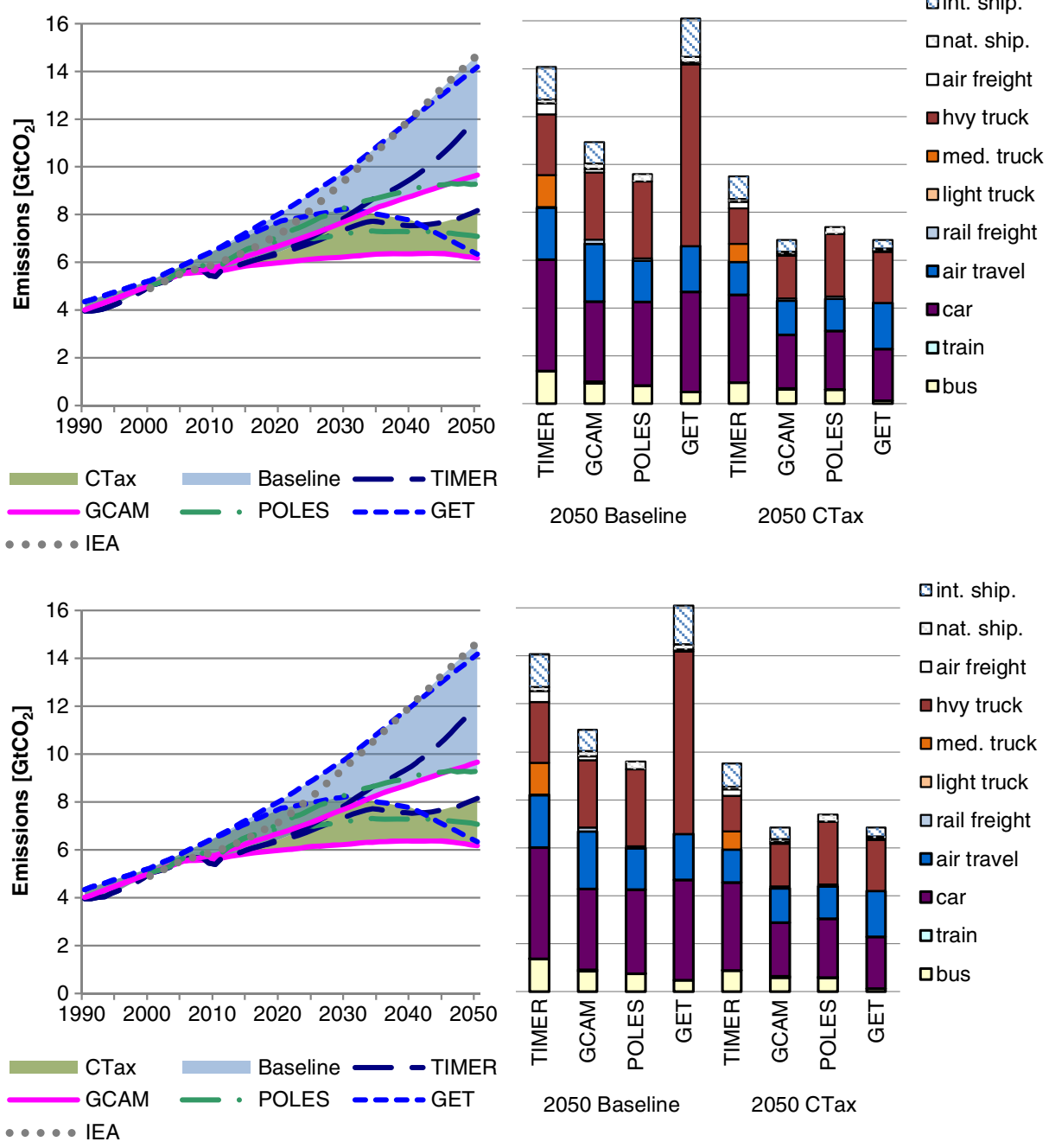

Fig. 4 Projections for direct $\mathrm{CO}_{2}$ emissions from transportation for 1990 to 2050 (excluding air and water freight) for the baseline and carbon tax (CTax) projections

\subsubsection{Impact on transport system}

The change in service demand in response to the carbon tax is modeled by POLES, TIMER and GCAM. By 2025 all three models project strongest decreases from the baseline in bus and air travel, and car travel to a lesser extent (see Figure S6). This is because the price sensitivity does not only depend on the energy intensity but on the share of energy costs on the total travel costs, which are high for air travel and buses, especially in developing regions. The lower effect in 2050 for POLES can be explained by the higher oil price in the baseline, reducing the sensitivity to the carbon tax. In GCAM and TIMER, travel by train increases compared to baseline by 2050 . 
Freight demand in GCAM indicates a shift from inland shipping, heavy truck and air freight to rail and international shipping. TIMER projects a reduction in all modes except international shipping, with most pronounced reduction for air freight (see Table S6).

With the carbon tax the global fuel use still increases, reaching 140 to 180 EJ per year by 2050 (see Figure S7). Regarding the fuel mix, the most significant change from the baseline is a reduction in fossil fuel use. In addition the four models see a slight increase in gas and biofuels use, which is most pronounced in GET (see Figure S8).

\subsubsection{Limitations of the climate mitigation runs}

The results of this study show more expensive mitigation potentials than McKinsey \& Co (2009), who estimate a reduction potential of $2.2 \mathrm{Gt} \mathrm{CO}_{2}$ per year by 2030 for about 100 USD per $\mathrm{tCO}_{2}$. For the evaluated model runs in 2035 carbon tax is around 85 USD per $\mathrm{tCO}_{2}$ and the annual reduction for cars amount 0.4 to $1.6 \mathrm{Gt} \mathrm{CO}_{2}$. The IEA (2009) Blue Map

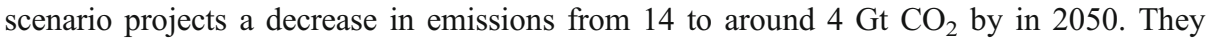
conclude that measures with marginal costs up to 200 USD per ton of $\mathrm{CO}_{2}$ saved or even higher, may be unavoidable for this target - which is consistent with our results.

The difference in the mitigation potential is influenced by oil price projection and technology costs assumptions, but can also be explained by the model approach. GCAM, POLES and TIMER are not full cost-optimization models; they evolve towards the lower cost path, while considering that investment decisions are not only driven by the cost representation in the model, preventing the winner-take-all behavior. This explains why GET using a cost minimizing approach with perfect foresight allows a higher reduction relative to the baseline.

\section{Conclusions}

The comparison of five transport models allows several conclusions to be derived for projections of direct $\mathrm{CO}_{2}$ emissions from transportation.

Using population and GDP projections from the OECD Environmental Outlook (OECD 2012), the five participating models project direct global $\mathrm{CO}_{2}$ emissions from transportation to increase from 5.5-6 Gt $\mathrm{CO}_{2}$ in 2005 to $9.3-14.7 \mathrm{Gt} \mathrm{CO}_{2}$ in 2050 (excluding shipping and airfreight). This large range equals an annual growth rate for $\mathrm{CO}_{2}$ emissions of $1.1 \%$ to $2.2 \%$ and results from growth differences in service demand (2.1 to $2.9 \%$ for travel and $1.8 \%$ to $2.8 \%$ for freight), energy intensity $(-0.2 \%$ to $-1.0 \%)$ and carbon intensity $(0.0 \%$ to $-0.5 \%)$. Since the global growth in service demand is to the largest extent due to the development of the transport system approaching the transport level observed in the USA today, one can affirm the technical feasibility of such growth. Regarding the growth in energy use, the limited availability of fossil fuel reserves and potentials of alternative fuels is considered by the models.

In all models $\mathrm{CO}_{2}$ emissions from cars, air travel and heavy trucks amount to more than $70 \%$ of total emissions from transport. The share of air travel in total emission increases. Other modes like bus, rail, and shipping considered by the transport models are relevant for service demand, but because of their comparatively high energy efficiency and low carbon intensity they contribute only little to global $\mathrm{CO}_{2}$ emissions. The increase in air travel is most pronounced in models that consider the increasing value of time costs for travel mode choices. Due to poor data especially in developing countries considerable differences exist even for baseline data. 
All models project future increases in energy use for transportation to take place outside current OECD regions, mainly in developing regions and by 2050 especially in Asia. Hence, improving projections on $\mathrm{CO}_{2}$ emissions from transportation requires also better understanding of transportation trends outside the OECD.

Up to 2050, all five models project that fossil liquid fuels remain dominant for fuel supply (above $72 \%$ ) in the baseline scenario. Large differences exist regarding when and which alternative fuels will replace oil. This uncertainty stems from different future technology cost assumptions that is reflected in deviating projections on future fuel prices. Different fossil fuel price projections also alter the penetration of more efficient vehicles with alternative fuel use and hence energy and carbon intensity of the transport modes.

The four models that evaluate the impact of a carbon tax increasing to $200 \mathrm{USD} / \mathrm{tCO}_{2}$ in 2050 project emissions to stabilize or decline by 2050 . The responses in relative terms ranges from 24 to $55 \%$ reductions in emissions compared to the baseline in 2050 . The different approaches to model price sensitivity of travel demand resulted in a shift in mode split to rail modes, however, the contribution of changing mode split to emission reduction is estimated to be minor compared to the other changes in the transport system. Decreasing the use of oil-based fuels is partially compensated by increasing biofuel and natural gas use. The contribution of lower transport service demand, efficiency increase, and fuel mix change to total $\mathrm{CO}_{2}$ emission reduction shows large differences across the models. To assess the mitigation potential from the transport sector, a better understanding of the price sensitivity of the transport system is required.

Acknowledgements Bastien Girod's contribution to this article has been funded by the Swiss National Science Foundation. We acknowledge Lew Fulton and the IEA ETP Transport Unit for running the IEA Transport model (MoMo) with the harmonized population and income projections and providing resulting output data.

\section{References}

Bandivadekar A, Bodek K, Cheah L, Evans C, Groode T, Heywood J, Kasseris E, Kromer M, Weiss M (2008) On the Road in 2035: Reducing Transportation's Petroleum Consumption and GHG Emissions. Laboratory for Energy and the Environment, Massachusetts Institute of Technology

Borken J, Steller H, Merétei T, Vanhove F (2007) Global and country inventory of road passenger and freight transportation: fuel consumption and emissions of air pollutants in year 2000. Transport Res Rec J Transport Res Board 2011:127-136

Davis SC, Diegel SW (2011) Transportation Energy Data Book: Edition 30. U.S. Department of Energy

EIA (2011) International Energy Outlook. U.S. Energy Information Administration, Office of Integrated Analysis and Forecasting, U.S. Department of Energy, Washington, DC

Eisentraut A (2010) Sustainable Production of Second-Generation Biofuels: Potential and Perspectives in Major Economies and Developing Countries. IEA

Fulton L, Eads G (2004) IEA/SMP Model Documentation and Reference Case Projection. WBCSD / IEA

Fulton L, Cazzola P, Cuenot F (2009) IEA mobility model (MoMo) and its use in the ETP 2008. Energ Pol $37: 3758-3768$

Girod B, Wiek A, Mieg H, Hulme M (2009) The evolution of the IPCC's emissions scenarios. Environ Sci Pol $12: 103-118$

Girod B, van Vuuren DP, Deetman S (2012) Global travel within the $2{ }^{\circ} \mathrm{C}$ climate target. Energ Pol 45:152166

Grahn M, Azar C, Williander MI, Anderson JE, Mueller SA, Wallington TJ (2009) Fuel and vehicle technology choices for passenger vehicles in achieving stringent CO2 targets: connections between transportation and other energy sectors. Environ Sci Technol 43:3365-3371

ICAO/CAEP Forecasting and Economic Sub-Group (2008) Traffic and fleet forecasts Paper presented to CAEP Steering Group. ICAO/CAEP 
IEA (2009) Transport, Energy and CO2. In Fulton L (ed). IEA, Paris

IEA (2010) Energy related CO2 Emissions. IEA

IPCC (2000) Special report on emissions scenarios. Cambridge University Press, Cambridge

IPCC (2007) Climate change 2007: synthesis report. Cambridge University Press, Cambridge

Kaya Y (1990) Impact of carbon dioxide emission control on GNP growth: interpretation of proposed scenarios. Paper presented to the IPCC energy and industry subgroup. Response Strategies Working Group, Paris

Kitous A, Criqui P, Bellevrat E, Chateau B (2010) Transformation patterns of the worldwide energy systemscenarios for the century with the POLES model. Energ J 31(1):49-82

Krey V, Clarke L (2011) Role of renewable energy in climate mitigation: a synthesis of recent scenarios. Clim Pol 11:1131-1158

Kyle P, Kim SH (2011) Long-term implications of alternative light-duty vehicle technologies for global greenhouse gas emissions and primary energy demands. Energ Pol 39:3012-3024

Lee JJ (2010) Can we accelerate the improvement of energy efficiency in aircraft systems? Energ Convers Manag 51:189-196

McKinsey \& Co (2009) Pathways to a Low-Carbon Economy-Version 2 of the Global Greenhouse Gas Abatement Cost Curve. McKinsey \& Company

OECD (2012) OECD environmental outlook. OECD, Paris

Owen B, Lee DS, Lim L (2010) Flying into the future: aviation emissions scenarios to 2050. Environ Sci Technol 44:2255-2260

Plotkin S, Singh M (2009) Multi-Path Transportation Futures Study:Vehicle Characterization and Scenario Analyses. Energy Systems Division, U.S. Department of Energy

Schafer A, Heywood J, Jacoby H, Waitz I (2010) Transportation in a climate-constrained world. MIT Press, Massachusetts

Takeshita T (2011) Global scenarios of air pollutant emissions from road transport through to 2050. Int J Environ Res Publ Health 8:3032-3062

Takeshita T, Yamaji K (2008) Important roles of fischer-tropsch synfuels in the global energy future. Energ Pol 36:2773-2784

Uherek E, Halenka T, Borken-Kleefeld J, Balkanski Y, Berntsen T, Borrego C, Gauss M, Hoor P, Juda-Rezler K, Lelieveld J, Melas D, Rypdal K, Schmid S (2010) Transport impacts on atmosphere and climate: land transport. Atmos Environ 44:4772-4816

UNFCCC (2010) The Cancun agreements: outcome of the work of the Ad Hoc working group on long-term cooperative action under the convention report of the conference of the parties 16 th session. UNFCCC, Cancun 